\title{
Burden of Disease, Unmet Needs in the Diagnosis and Management of Atopic Dermatitis: An Indian Expert Consensus
}

\author{
Murlidhar Rajagopalan' \\ Amar Jeet Chitkara ${ }^{2}$ \\ Samir Dalwai ${ }^{3}$ \\ Abhishek $\mathrm{De}^{4}$ \\ Ram Gulati ${ }^{5}$ \\ Samipa Mukherjee ${ }^{6}$ \\ Sharad Mutalik ${ }^{7}$ \\ Nidhi Sharma ${ }^{8}$ \\ Shrutakirthi Shenoi $\mathbb{1 D}^{9}$ \\ Prakash Vaidya ${ }^{10}$ \\ Amod Tilak ${ }^{\prime \prime}$ \\ Charles Adhav' "
}

'Department of Dermatology, Apollo Hospitals, Chennai, Tamil Nadu, India;

${ }^{2}$ Department of Pediatrics, Max Super Specialty Hospital, Shalimar Bagh, Delhi, India; ${ }^{3} \mathrm{New}$ Horizons Child

Development Center, Mumbai,

Maharashtra, India; ${ }^{4}$ Department of

Dermatology, Calcutta National Medical

College, Kolkata, West Bengal, India;

${ }^{5}$ SDM Hospital, Jaipur, Rajasthan, India;

${ }^{6}$ Cloudnine Hospitals, Bengaluru,

Karnataka, India; ${ }^{7}$ Department of

Dermatology, Maharashtra Medical

Foundation, Pune, Maharashtra, India;

${ }^{8}$ Medanta Hospital, Gurugram, Haryana, India; 'Department of Dermatology,

Kanachur Institute of Medical Sciences,

Mangaluru, Karnataka, India;

${ }^{10}$ Department of Pediatrics and

Neonatology, Fortis Hospital, Mulund,

Maharashtra, India; " $P f i z e r$ India Ltd.,

Pfizer Biopharmaceuticals Group

(Emerging Markets), Mumbai, India

Correspondence: Murlidhar Rajagopalan Department of Dermatology, Apollo Hospitals, Chennai, Tamil Nadu, India Tel +9l 9840045500

Email murlilata@gmail.com
Background: Atopic dermatitis (AD) is a chronic inflammatory, non-communicable, and relapsing skin disease that affects all age groups. There is a dearth of literature that reports the disease burden, and epidemiology and highlights unmet needs in the diagnosis and management of AD in India.

Methods: A total of ten specialists including dermatologists, pediatric dermatologists, and pediatricians with more than ten years of experience and practicing in different parts of India served as the expert panel during the virtual meet conducted on January 24, 2021. A questionnaire comprising 32 questions on different aspects of $\mathrm{AD}$ management was categorized among different sections: burden of disease (five questions), age of onset and prevalence (five questions), etiology and pathogenesis (six questions), diagnosis and severity of the disease (seven questions), and treatment (nine questions). Consensus was defined when agreement was provided by $\geq 90 \%$ of the experts.

Results: Considering the profound impact $\mathrm{AD}$ has on the quality of life (QoL) of patients, the expert panel recommended patient counseling while moderate to severe cases of AD need a prompt referral to a specialist. The panel did not recommend any specific diagnostic and severity criteria as a standard due to the inherent limitations associated with every criterion. The role of environment and changing lifestyle in addition to genetic and familial risk factors for $\mathrm{AD}$ was also considered. The panel unanimously recommended to conduct a countrywide, multicenter survey/study to estimate the true prevalence of $\mathrm{AD}$ in India. Further, the experts recommended to follow proper treatment protocols and to perform longitudinal monitoring for understanding corticosteroid treatment associated side effects.

Conclusion: This guidance focuses on identifying the unmet gaps and provides practical recommendations for improving QoL, diagnosis, prognosis, and overall management of patients with $\mathrm{AD}$ in India.

Keywords: consensus development, cost of illness, dermatologist, epidemiology, pediatrician, quality of life

\section{Introduction}

Atopic dermatitis (AD) is a chronic inflammatory, non-communicable, and relapsing skin disease that most often develops during early infancy and childhood. ${ }^{1} \mathrm{AD}$ developed during childhood is characterized by eczematous lesions on the flexural areas, nape of the neck, dorsum of the feet and hands; whereas, lichenified/exudative flexural dermatitis alone or associated with head/neck, and hand eczema, and the prurigo nodularis ( $\mathrm{PN}$ )-like $\mathrm{AD}$ are commonly observed in adult patients with $\mathrm{AD}^{2-4}$ Owing to these manifestations, patients with $\mathrm{AD}$ may experience 
itching, sleep disturbances, poor performance at school/ work, and disturbed social, mental, and emotional functioning. ${ }^{1,5}$ Furthermore, childhood $\mathrm{AD}$ has also shown a negative impact on the quality of life (QoL) of the patient's family and caregivers. ${ }^{5,6} \mathrm{AD}$ is also associated with several "other atopic diseases" including asthma, allergic rhinitis, food allergies, and hay fever, whose prevalence vary by age ${ }^{7} \mathrm{AD}$ also increases the risk of other non-allergic comorbidities including mental health disorders and other autoimmune- or immunemediated diseases. ${ }^{1}$

The Global Burden of Skin Disease study (2010) estimated that $\mathrm{AD}$ affects up to 230 million people worldwide with a higher prevalence in females and lower prevalence in older age groups. ${ }^{8,9}$ The Global Burden of Disease study reported that the prevalence of $\mathrm{AD}$ and disabilityadjusted life years (DALYs) in adults have remained stable since 1990 till 2017. ${ }^{10}$ As per the International Study of Asthma and Allergies in Childhood (ISAAC), prevalence of AD in India (6-7 years: $2.7 \%$ and $13-14$ years: $3.6 \%$ ) was lower compared to the global estimates. ${ }^{11}$

A number of hospital-based or region-specific studies have assessed the prevalence of AD in India; ${ }^{12-15}$ while region-specific-differences in prevalence are likely due to the different climatic conditions. ${ }^{16,17}$ In this regard, nationwide, systematic studies identifying the disease burden, epidemiology, and challenges in the diagnosis and management of $\mathrm{AD}$ in India are lacking.

The primary objective of this consensus meeting was to identify the need gaps and to provide practical guidance to understand the prevalence, diagnosis, and management of $\mathrm{AD}$ in India.

\section{Methods}

To understand the region-specific differences in terms of prevalence, diagnosis, and management of $\mathrm{AD}$, the expert panel included ten specialists including dermatologists, pediatric dermatologists, and pediatricians with more than ten years of experience and practicing in different parts of India was convened. Dr. Amod Tilak and Dr. Charles Adhav coordinated with the expert panel, analyzed the results, and were responsible for the overall organizational and logistic aspects of the project. The expert discussion was moderated by Dr. Murlidhar Rajagopalan. The expert panel consisted of Dr. Ram Gulati, Dr. Nidhi Sharma, Dr. Amarjeet Chitkara, Dr. Abhishek De, Dr. Sharad Mutalik, Dr. Prakash
Vaidya, Dr. Samir Dalwai, Dr. Shrutakirthi Shenoi, and Dr. Samipa Mukherjee.

The ethical committee approval was not applicable, as this article is based on previously conducted studies and does not contain involvement with human participants or animals.

\section{Questionnaire and Compilation of Tentative Consensus}

A rapid review of global and regional data on the management of $\mathrm{AD}$ was conducted. The panel members decided to include questions on different aspects of the disease including humanistic and economic burden, prevalence, diagnosis, severity, and treatment of AD. The questionnaire was developed and curated by the Chairperson; further, he consulted other panel members during the meeting to add/modify certain questions.

A questionnaire comprising 32 questions (Supplementary Table 1) on different aspects of AD management was categorized among different sections: burden of disease (five questions), age of onset and prevalence (five questions), etiology and pathogenesis (six questions), diagnosis and severity of the disease (seven questions), and treatment (nine questions). Majority of the questions were formulated such that the experts could provide response from the options "Agree," "Disagree," and "Partially Agree." However, a few open-ended questions had specific options to initiate further discussion. "Consensus" was defined when agreement was provided by $\geq 90 \%$ of the experts.

All the panel members were allowed to share their personal experiences and answer the clinical questions enlisted under each topic. The virtual meet was conducted on January 24, 2021. This manuscript is the outcome of the expert panel discussion and consensus arrived during the meeting.

\section{Results and Discussion}

\section{Burden of Disease}

Adult patients with AD experience substantially impaired health-related QoL as a result of itching and scratching, mood and sleep disorders, negative emotions compared with the general population and patients with other chronic diseases such as diabetes mellitus and hypertension. ${ }^{6}$ Furthermore, AD is also associated with high levels of stigmatization, societal rejection, anxiety, depression, and suicidal ideation. ${ }^{18}$ School-going children (aged $>8$ years) 
can experience bullying and avoidance resulting in lack of self-esteem, social withdrawal, and rejection. ${ }^{5,6}$

As per Handa et al over a 6-month period, the cost of $\mathrm{AD}$ treatment was Rs. $6235.00 \pm 3514.00$; the mean total costs increased significantly with the severity and ranged approximately between Rs. 3500 and 8990 (mild AD: Rs. $3579.00 \pm 948.00$, moderate AD: Rs. $6806.00 \pm 3676.00$ and severe AD: Rs. $8991.00 \pm$ 3129.00) in an outpatient hospital setting. Caregiver cost constituted half of the total cost, followed by indirect cost $(31.7 \%)$, and provider cost $(18.1 \%){ }^{19}$ It is important to note that the direct comparison of total treatment cost of $\mathrm{AD}$ with other chronic diseases is difficult considering the duration, severity, and nature of the disease, and patient- and caregiver-specific characteristics (location: rural/urban, age, education, annual income, community/ tertiary care hospitals, outpatient clinics, specialty and so on).

The experts echoed with the published literature on the burden of the disease (Table 1). In addition to busy outpatient clinic, lack of training on patient communication and counseling, and inadequate knowledge of patients were considered as the major deterrents. The direct costs (cost of medication and hospitalization) contribute more toward the total costs of mild-to-moderate $\mathrm{AD}$, whereas direct and indirect costs contribute equally in moderate-tosevere $\mathrm{AD}$. The panel suggested that a prompt referral to a specialist may reduce the symptomatic and economic burden in patients with $\mathrm{AD}$; however, it depends on the area of practice (rural/urban setting) in India.

\section{Diagnosis}

The clinical diagnosis of $\mathrm{AD}$ is mainly based on the physical examination and personal/family history of atopy and not on a definitive laboratory test. ${ }^{20,21}$ Commonly used diagnostic criteria include Hanifin-Rajka (HR), the United Kingdom (UK) Working Party, and the modified American Academy of Dermatology (AAD) criteria; however each criteria is associated with inherent limitations. ${ }^{20,22}$ A systematic review of randomized controlled trials (RCT; $\mathrm{N}=212$ ) conducted between 2007 and 2016, including adult and pediatric patients with AD, reported that among 10 different diagnostic criteria, HR criteria (41.0\%) was the most commonly used followed by the UK refinement of the HR criteria $(9.0 \%)$ and AAD criteria $(3.8 \%){ }^{23}$ Although the most common clinical features associated with $\mathrm{AD}$ are pruritus, lichenification, and xerosis, inconsistency or deviation from the classical pattern especially in adult patients can often make it the diagnosis of exclusion. ${ }^{24}$

About $44 \%$ of experts recommended HR followed by UK working party (33\%), and AAD revised of UK Working Party criteria (22\%) for diagnosis of $\mathrm{AD}$. However, considering practical limitations associated with every diagnostic criterion, the expert panel did not reach consensus on recommending a standard criterion for diagnosis of $\mathrm{AD}$.

\section{Severity of the Disease}

A simplified severity assessment of $\mathrm{AD}$ includes (Figure 1): (a) measuring the area involved in percentage of body surface; (b) establishing acute, subacute, or chronic changes; and (c) determining the impact on patient's QoL. ${ }^{25}$ The severity of dermatitis can be measured and monitored in several ways including the adequately validated and user-friendly scales such as: Scoring Atopic Dermatitis (SCORAD), Objective Severity Assessment of Atopic dermatitis (OSAAD), The Eczema Area and Severity Index (EASI), and Patient-Oriented Eczema Measure (POEM); however, there is no standard measure yet to understand the disease severity in clinical practice. $^{22,25}$

An equal proportion (25\%) of experts recommended EASI and POEM, whereas $37 \%$ recommended Investigator's Static Global Assessment for determining severity of AD; regardless of scoring system, the experts highlighted to consider Dermatology Life Quality Index in routine management.

\section{Age of Onset of Atopic Dermatitis}

In about $80 \%$ of patients, $\mathrm{AD}$ is developed before six years of age. ${ }^{1} \mathrm{AD}$ is less persistent when developed before two years of age, whereas onset at a later stage can result in greater severity and more persistent $\mathrm{AD} .^{26}$

A study conducted in the eastern part of India reported that the mean age of onset in the "infantile AD" group, and in the "childhood AD" group was 5.2 months and 3.47 years, respectively. ${ }^{12}$ Other studies including children aged 2 to 12 years reported mean age of onset as 3.63 years and 4.58 years. $^{13,27}$

Although majority of experts $(70 \%)$ responded that the mean age of onset in India for infantile AD is between 3 and 6 months and childhood AD is between 3 and 5 years, exact estimation is challenging due to: (a) lack of simple and consistent definition; (b) challenges in interpreting the clinical symptoms in infants due to lack of awareness and 
Table I Consensus Statements

\begin{tabular}{|c|c|c|}
\hline Consensus Statements & $\begin{array}{l}\text { Voting } \\
\text { Results }^{\mathrm{a}}\end{array}$ & Consensus \\
\hline \multicolumn{3}{|l|}{ Burden of Disease } \\
\hline $\begin{array}{l}\text { Practicing clinicians are largely cognizant of the significant psychological burden AD has on patients. However, there } \\
\text { is a need for more sensitization for estimating the psychological burden }\end{array}$ & $10 / 10$ & $100 \%$ \\
\hline $\begin{array}{l}\text { A proactive communication, follow-up calls, patient counseling, and education can improve treatment compliance } \\
\text { and strengthen patient-physician relationship }\end{array}$ & $10 / 10$ & $100 \%$ \\
\hline $\begin{array}{l}\text { Due to the chronic, recurrent nature of the disease, cost incurred for the treatment of moderate-to-severe AD is } \\
\text { comparable to other chronic illness such as diabetes }\end{array}$ & $10 / 10$ & $100 \%$ \\
\hline $\begin{array}{l}\text { Multiple factors such as reducing frequency of hospital visits, cost of medication, and providing social cover can } \\
\text { reduce the cost of care; however, prompt referral to the specialist in the early stage can reduce humanistic and } \\
\text { economic burden of disease }\end{array}$ & $10 / 10$ & $100 \%$ \\
\hline \multicolumn{3}{|l|}{ Diagnosis and Severity of Disease } \\
\hline $\begin{array}{l}\text { It is important to consider the burden of symptoms while assessing severity of the disease. Additionally, there is } \\
\text { a strong need to consider the psychological, social, and monetary impact the disease has on the patient and family } \\
\text { members/caregivers/parents }\end{array}$ & $9 / 10$ & $90 \%$ \\
\hline \multicolumn{3}{|l|}{ True Estimation of AD is Difficult due to Inconsistent Definition } \\
\hline There is a need for a clear and simple definition of $A D$ to estimate its true prevalence in India & $10 / 10$ & $100 \%$ \\
\hline $\begin{array}{l}\text { There is a lack of countrywide, multicenter survey/study that makes it difficult to estimate the true prevalence } \\
\text { of } A D \text { in India }\end{array}$ & 9/9 & $100 \%$ \\
\hline \multicolumn{3}{|l|}{ Etiopathogenesis of AD } \\
\hline A combination of environmental, genetic and familial factors is responsible for $A D$ & $10 / 10$ & $100 \%$ \\
\hline $\begin{array}{l}\text { A complex interplay of urbanization, environmental (the effect of weather and humidity), and diet may contribute } \\
\text { towards the region-specific differences in } A D\end{array}$ & $10 / 10$ & $100 \%$ \\
\hline \multicolumn{3}{|l|}{ Other Statements with $\geq 75 \%$ Agreement } \\
\hline In majority of cases, $A D$ is underestimated/underdiagnosed in India & $8 / 10$ & $80 \%$ \\
\hline $\begin{array}{l}\text { Some of the minor symptoms from Hanifin and Rajka criteria are non-significant in the Indian context due to } \\
\text { a combination of clinical and genetic factors, along with inconsistencies in the definition of } A D \text {, and a higher } \\
\text { proportion of patients presenting with mild disease }\end{array}$ & $7 / 9$ & $77 \%$ \\
\hline $\begin{array}{l}\text { Patients approach clinicians once home remedies or other treatments do not provide respite; however, this could } \\
\text { be specific to the location of practice but largely remains case-specific }\end{array}$ & $8 / 9$ & $88 \%$ \\
\hline The prevalence of childhood AD is more than adolescent/early adulthood AD & $8 / 10$ & $80 \%$ \\
\hline $\begin{array}{l}\text { Duration of interaction with a patient is case-specific and depends on the severity of the disease, age of patient, and } \\
\text { other patient-specific factors }\end{array}$ & $7 / 8$ & $87 \%$ \\
\hline $\begin{array}{l}\text { Regardless of the age of patients, both (adult or children) are equally non-compliant to TCS treatment as suggested } \\
\text { by the clinician and hence require counseling and awareness }\end{array}$ & $7 / 9$ & $77 \%$ \\
\hline $\begin{array}{l}\text { Following SCS treatment, Indian patients with AD rarely experience glaucoma, cataract, osteoporosis, and adrenal } \\
\text { insufficiency }\end{array}$ & $7 / 9$ & $77 \%$ \\
\hline
\end{tabular}

Note: ${ }^{2}$ Number of experts who agreed/ number of experts who voted.

Abbreviations: AD, atopic dermatitis; SCS, systemic corticosteroids; TCS, topical corticosteroids. 


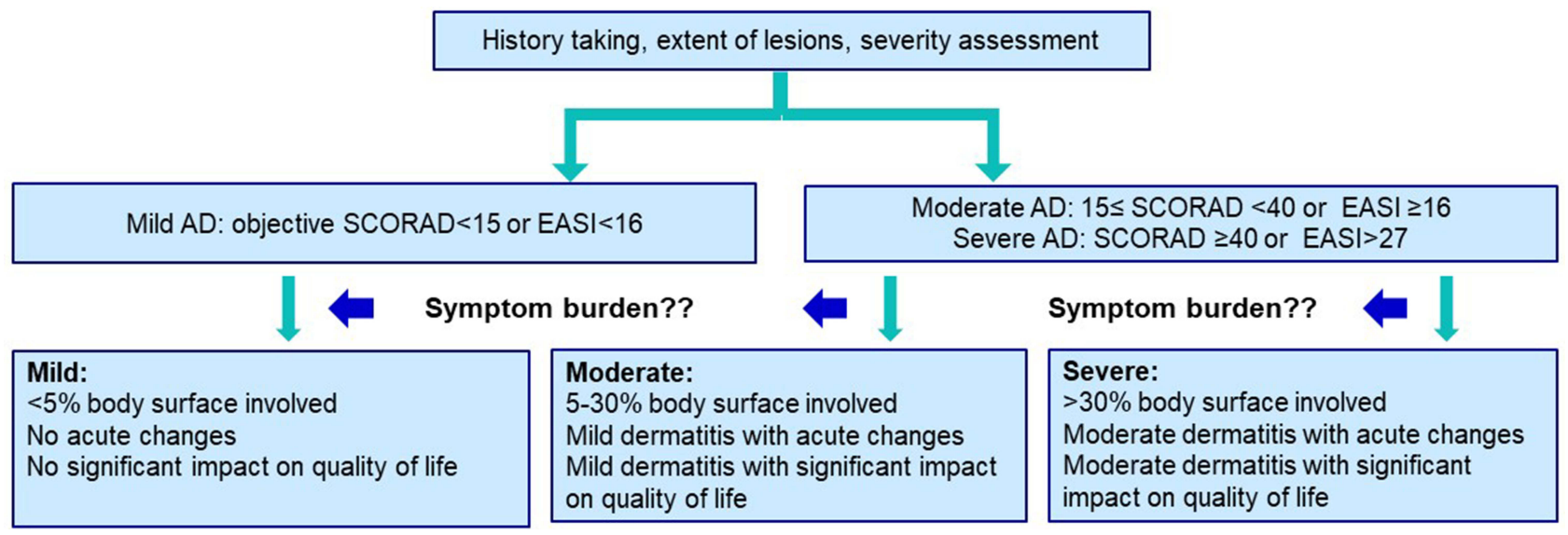

Figure I Classification of AD based on severity. Data from ${ }^{25,47}$.

Abbreviations: AD, atopic dermatitis; EASI, The Eczema Area and Severity Index; SCORAD, Scoring Atopic Dermatitis.

inaccurate history provided by the parents/caregivers; (c) diagnosis of exclusion due to common presentations including infantile rash (nappy rash), fungal infection, and contact dermatitis.

\section{Prevalence of Atopic Dermatitis}

A number of previously published region-specific studies have reported variation in terms of prevalence of $\mathrm{AD}$ in India (Table 2). In this regard, the expert panel unanimously agreed to conduct a countrywide, multicenter survey/study that would estimate the true prevalence of $\mathrm{AD}$ in India (Table 1).

A great variation was also observed in terms of genderspecific risk of AD. A study conducted among schoolgoing children reported male to female ratio of 1:1.73 including $42.2 \%$ boys and $57.8 \%$ girls. ${ }^{15}$ Conversely, studies by Kumar et al and Dhar et al reported male predominance in infant and childhood groups. ${ }^{12,27}$ More than half of the experts $(60 \%)$ agreed that male and female are at equal risk of developing $\mathrm{AD}$. However, preponderance of male patients could be observed due to sociocultural biases (gender disparity, taboo associated with skin diseases), and protective role of estrogen in females.

\section{Etiology of Atopic Dermatitis}

$\mathrm{AD}$, a multifactorial disease, is due to the interaction between genetic, immunological, and environmental factors (Table 3). ${ }^{28,29}$ In addition to filaggrin, there are other genes that could be responsible for skin barrier impairment. The majority of panel members (70\%) did not recommend performing gene profiling routinely, due to cost constraints and inadequate resources; however, its potential in the near future was not denied. A few experts $(30 \%)$ specified that gene profiling may avoid unnecessary exposure to steroids and other topical/systemic drugs and may reduce multiple treatments in patients with $\mathrm{AD}$. The expert panel indicated temperature, humidity, air pollution, tobacco smoke, urban versus rural living, family size, and antibiotics as some of the environmental risk factors for $\mathrm{AD}$ that are aligned with those published in the literature (Table 1). ${ }^{1}$ The panel did not consider diet as one of the major trigger factors, as the dietary habits (wheat-based, dairy products) have been relatively consistent over the centuries. However, recent changes in the lifestyle and adoption of western diet can be considered as one of the trigger factors for $\mathrm{AD}$ in India.

\section{Pathogenesis of Atopic Dermatitis}

Pathogenesis of $\mathrm{AD}$ is multifactorial and complex in nature, which includes skin barrier dysfunction, immunological (cutaneous and systemic) dysregulation, and dysbiosis of resident microbiota (Figure 2). ${ }^{28,29}$

It is important to note that not all microbial infections are protective against AD. Specifically, colonization of $S$ aureus was observed in 70\% lesional skin, 39\% non-lesional skin, and $62 \%$ nose of patients with $\mathrm{AD} .{ }^{30}$ In a cross-sectional study conducted in southern India, $S$. aureus was present on the lesional and non-lesional skin of $92.4 \%$ of children aged $<12$ years with $\mathrm{AD}^{31}$ About $60 \%$ of experts agreed that patients with moderate-to-severe $\mathrm{AD}$ are susceptible to $S$ aureus infection likely due to itching, disruption of skin 


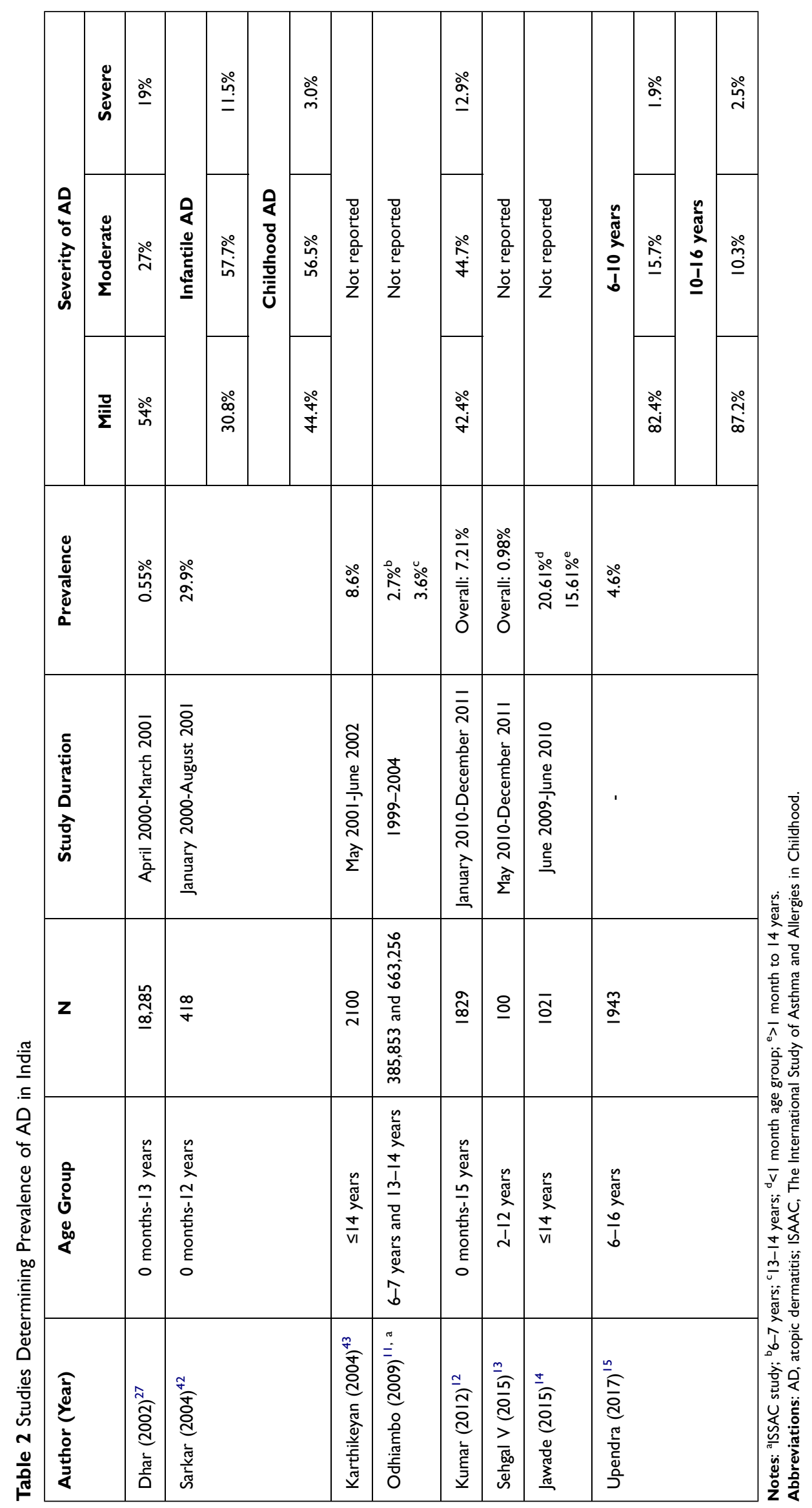


Table 3 Etiology of AD

\section{Genetic Factors}

- Loss of function mutations in the FLG gene is the strongest known genetic risk factor. ${ }^{7}$

o Associated with skin barrier impairment, increased TEWL, greater penetration of allergens, and increased risk of persistent $A D{ }^{7}$

- In a prospective, case-control study, the prevalence of FLG mutations were common in north Indian patients with hand eczema than controls $(33.7 \%$ vs $3.5 \%){ }^{44}$

o Mutations in S2889X constituted $96.4 \%$ of all FLG mutations.

o FLG mutations were associated with irritant contact dermatitis with or without atopy, allergic contact dermatitis with or without atopy, and idiopathic subtypes.

- Malassezia yeast in AD acts as an allergenic aggravating factor provoking recurrent episodes of $A D$ symptoms. ${ }^{45}$ - A prospective study in India has shown higher isolation rate of Malassezia yeast in cases compared to controls (63.1\% vs $52.6 \%$ ).

\section{Familial Factors}

- Approximately $70 \%$ of patients are estimated to have a positive family history. ${ }^{1,7}$

o 2- to 3-fold increased odds when one parent is affected.

o 3- to 6-fold if both the parents are affected.

- 1.5-fold if one of the parents suffer from any atopic disease.

- Studies conducted in India have shown a wide variation in the proportion of patients with personal (I5-54\%) and family history (36-65\%) for AD. o A study conducted in north India reported that the childhood AD group had patients with personal history (I5.37\%), family history (36.37\%), and both personal and family history (7.36\%) of atopy. ${ }^{46}$

o In another study, $54 \%$ of patients had personal history and $65 \%$ of patients had family history of atopy. ${ }^{27}$

o Sarkar et al reported that $\mathbf{4 2 . 3 \%}$ from infant group and $35.35 \%$ from childhood group had family history of atopy while in the childhood group $7.07 \%$ had personal history, and $2.02 \%$ had both personal and family history of atopy. ${ }^{42}$

\section{Environmental Risk Factors'}

- Air temperature and humidity

- Tobacco smoke

- Low UV light exposure

- Food allergies

- Living in an urban setting

- Consuming a diet high in sugars and polyunsaturated fatty acids

- Repeated exposure to antibiotics before 5 years of age

- Small family size

- High education level of household

- Studies conducted in India showed eczema aggravation in winters due to decreased moisture than summers. o A study in north Indian children showed that $62 \%$ of patients had exacerbations in winter while $17 \%$ experienced it in summer. ${ }^{42}$ Similar findings were observed by Dhar et al among infants. (67.14\% vs $23.36 \%$ ) and children (58\% vs $32.9 \%)$ in winters and summers, respectively. ${ }^{46}$ - On the contrary, a study in eastern India reported that a higher proportion of patients had aggravation in summer compared to winter (40\% vs $15 \%)^{27}$

Abbreviations: AD, atopic dermatitis; FLG, filaggrin; TEWL, transepidermal water loss; UV, ultraviolet.

barrier, and poor hand hygiene. The majority of experts who agreed and responded partial applicability of hygiene hypothesis were $40 \%$ and $50 \%$, respectively. The panel recommended to conduct a high-powered systematic study in urban and rural settings for a better understanding of the role of hygiene hypothesis in India.

\section{Treatment of Atopic Dermatitis}

Due to chronic nature of the disease, the ideal long-term management of $\mathrm{AD}$ includes managing cutaneous and systemic inflammation. In most cases, $\mathrm{AD}$ is managed by controlling exacerbation factors, good general skin care, and topical treatments. Good skin care routine, ${ }^{21,32}$ and patient and caregiver education on treatment doses together with skin-care techniques ${ }^{21,32,33}$ are some of the important aspects of overall self-management of $\mathrm{AD}$. Additionally, psychological interventions such as brief dynamic psychotherapy, cognitive-behavioral therapy, biofeedback, relaxation training, hypnosis, distraction, and habit reversal could be used to reduce itch intensity, 


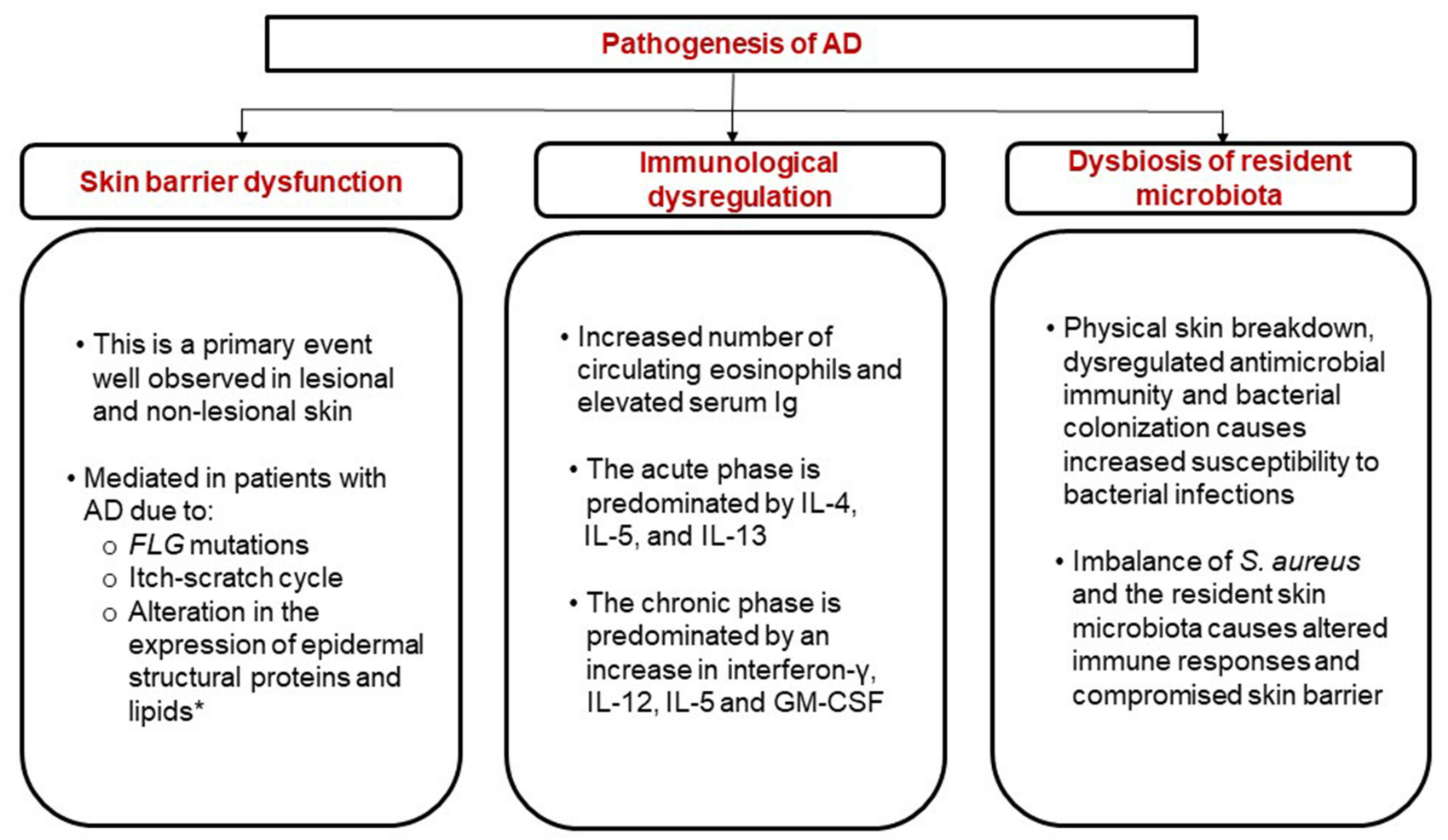

Figure 2 Pathogenesis of AD. Data from ${ }^{1,29,48}$.

Notes: *Lipids include cyclic adenosine monophosphate, cathelicidin and beta-defensins. Epidermal barrier proteins include FLG, keratins, loricrin, involucrin and intercellular proteins

Abbreviations: AD, atopic dermatitis; CD, cluster of differentiation; FLG, filaggrin; GM-CSF, granulocyte-macrophage colony-stimulating factor; Ig, immunoglobulin; IL, interleukin; S. aureus, Staphylococcus aureus

disease severity, and scratching in adult patients with AD. ${ }^{18,33}$ Distraction and redirection to hands-on activities can be recommended to pediatric patients. ${ }^{33}$

\section{First-Line Therapy}

\section{Topical Corticosteroids}

Topical corticosteroids (TCS) are used as the first-line treatment in the management of acute $\mathrm{AD}$ flare-ups by decreasing the inflammatory immune response resulting in rapid relief. ${ }^{34} \mathrm{~A}$ scoping systematic review of nine RCTs reported that a large proportion of participants responded to TCS treatment compared to placebo and proactive treatment (16 weeks) prevented flare-ups during the treatment period. ${ }^{35}$ There is a little consensus on the frequency of application (once daily/twice daily or more frequent use) due to similar efficacy. ${ }^{35,36}$ Possible adverse effects of TCS include skin atrophy, purpura, telangiectasia, striae, hypopigmentation, and acneiform eruption. ${ }^{34,37}$

\section{Systemic Corticosteroids}

According to the International Eczema Council, systemic corticosteroids (SCS) are not recommended for routine use and may be used only in specific circumstances for the treatment of severe AD. However, the treatment duration of SCS should be limited to short duration as a bridge to steroid-sparing therapies. ${ }^{38}$ Noted adverse events include rebound $\mathrm{AD}$ flares, adrenal suppression, growth retardation, hypertension, and weight gain. ${ }^{39}$ The most recent AAD guidelines recommend tapered schedule during the use of SCS to decrease the risk of adrenal suppression. ${ }^{40}$

About $66 \%$ of experts responded that glaucoma, cataract, and adrenal insufficiency are rarely observed in Indian patients with $\mathrm{AD}$, while the majority of experts reported that skin atrophy, acneiform eruption, and hypopigmentation are commonly reported as TCS-associated side effects. The panel was divided into two groups on reporting "steroid addiction" that is associated with prolonged self-medication. Conversely, majority of experts expressed non-compliance to TCS treatment (Table 1) owing to various factors such as: (a) patient-physician relationship; (b) lack of communication; (c) corticosteroid phobia or fear of side effects. More than half of the experts (57\%) 
Table 4 Expert Panel Recommendations on the Management of AD in India

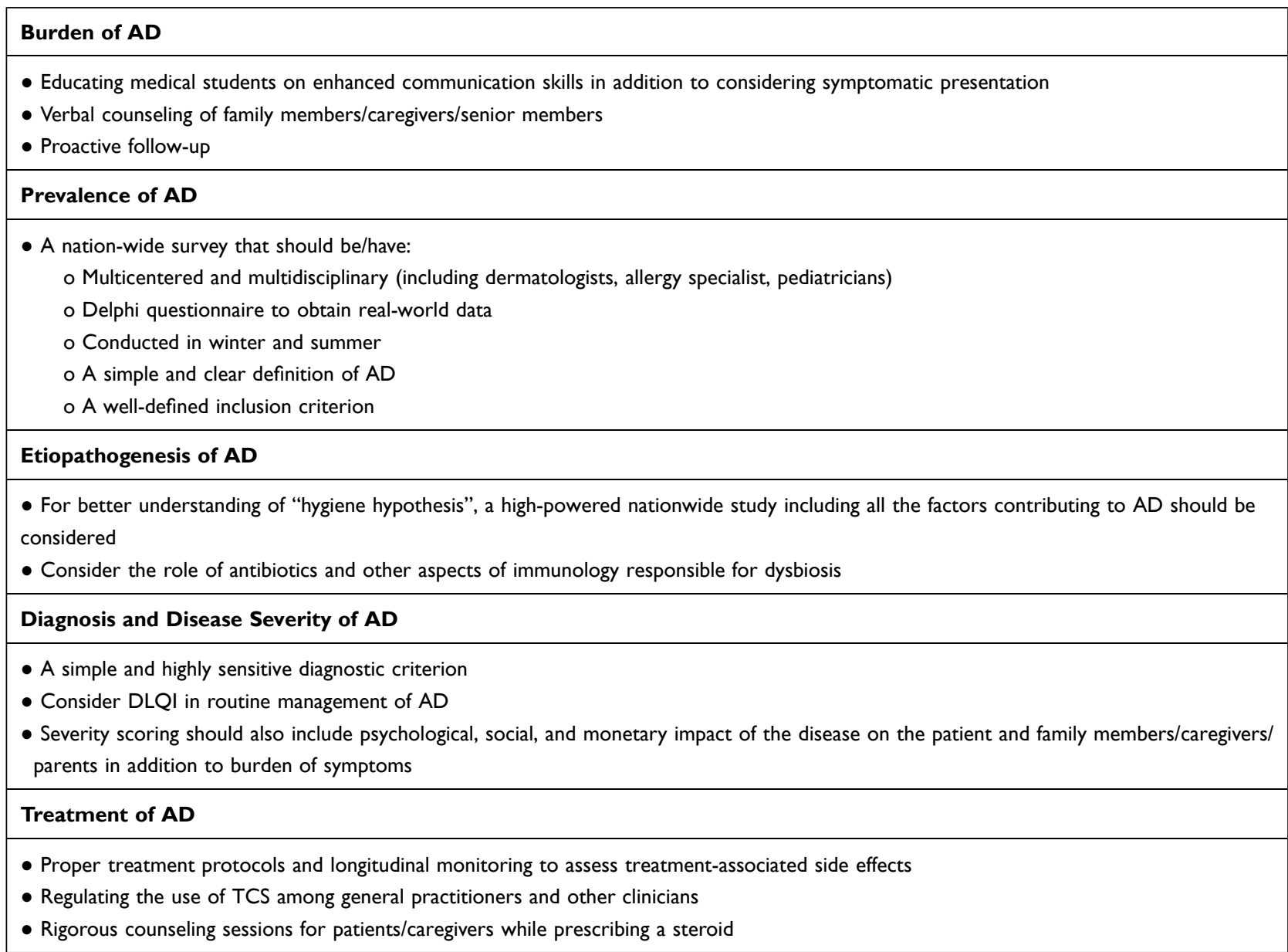

Abbreviations: AD, atopic dermatitis; DLQI, Dermatology Life Quality Index; QoL, quality of life; TCS, topical corticosteroids.

indicated that Indian patients following SCS treatment report hypertension, weight gain, behavioral changes, and opportunistic infections. The panel emphasized that treatment-associated side effects do exist and hence clinicians should follow proper treatment protocols and perform longitudinal monitoring.

\section{Second-Line Therapy}

Phototherapy is recommended as a second-line treatment either as a monotherapy or as an adjuvant to emollients and steroids in patients with moderate-to-severe $\mathrm{AD}^{40}$ Commonly reported side effects associated with phototherapy include xerosis cutis, treatment-induced erythema, and burning of skin. Long-term adverse effects particularly due to high dosage of UVA1 include photodamage, skin carcinogenesis, and melanoma induction. ${ }^{32,41}$

Systemic immunomodulating agents are recommended for the treatment of adult and pediatric patients with moderate-to-severe $\mathrm{AD}$ when topical regimens and/or phototherapy fail or when QoL is substantially impacted. ${ }^{40}$ Effective off-label systemic treatment options include cyclosporine, azathioprine, methotrexate, and mycophenolate mofetil. ${ }^{40}$

\section{Summary}

$\mathrm{AD}$, a multifactorial disease, disproportionately affects health-related QoL and social, mental, and emotional functioning in both, patients and parents/caregivers. To understand the unmet need in the overall management of $\mathrm{AD}$, the expert panel including dermatologists across India proactively discussed, shared their experiences, and provided recommendations (Table 4) in terms of estimating prevalence, etiopathogenesis, diagnosis, and severity of the disease, and treatment of AD. These consensus statements aim to provide a practical guidance to dermatologists, pediatricians, and primary care physicians while treating patients with $\mathrm{AD}$ in India. 
The panel acknowledged the burden $\mathrm{AD}$ has on patients and suggested focused training on patient communication and counseling. Lack of simple and uniform definition of $\mathrm{AD}$, varied clinical presentation, cultural biases, and inadequate knowledge about the disease makes estimation of prevalence, gender ratio, and age of onset difficult in the clinical practice. There was no consensus on using a specific diagnostic criteria and severity scoring as standard due to inherent drawbacks associated with every criterion or tool. However, experts recommended to consider QoL and symptom burden while determining the severity of the disease. Furthermore, the panel acknowledged the occurrence of commonly reported side effects following TCS or SCS or systemic therapy among Indian patients. In this regard, it is important to consider that treatment-associated side effects do exist and hence, clinicians should follow proper treatment protocols and should perform longitudinal monitoring.

This guidance focuses on identifying the unmet gaps and provides practical recommendations for improved QoL, diagnosis, prognosis, and overall management of patients with AD in India.

\section{Acknowledgments}

Medical writing support was provided by Ashwini Atre, PhD and Sumedha Kulkarni, M. Pharm of Indegene Pvt. Ltd. Bangalore, India and that was funded by Pfizer India Ltd.

\section{Funding}

This study was funded by Pfizer India Ltd.

\section{Disclosure}

Dr. Sharad Mutalik is on the advisory board of Novartis, Pfizer, Dr Reddy Labs and Sanofi and receives remuneration for the same. Dr. Shrutakirthi Shenoi reports personal fees from Pfizer India Ltd, during the conduct of the study. Dr. Amod and Dr. Charles are employees of Pfizer ltd. The authors report no other conflicts of interest in this work.

\section{References}

1. Weidinger S, Beck LA, Bieber T, Kabashima K, Irvine AD. Atopic dermatitis. Nat Rev Dis Prim. 2018;4(1). doi:10.1038/s41572-0180001-z

2. Nettis E, Ortoncelli M, Pellacani G, et al. A multicenter study on the prevalence of clinical patterns and clinical phenotypes in adult atopic dermatitis. J Investig Allergol Clin Immunol. 2020;30(6):448-472. doi:10.18176/jiaci.0519
3. Silverberg JI, Vakharia PP, Chopra R, et al. Phenotypical differences of childhood- and adult-onset atopic dermatitis. J Allergy Clin Immunol Pract. 2018;6(4):1306-1312. doi:10.1016/j. jaip.2017.10.005

4. Ozkaya E. Adult-onset atopic dermatitis. J Am Acad Dermatol. 2005;52(4):579-582. doi:10.1016/j.jaad.2004.11.037

5. Lifschitz C. The impact of atopic dermatitis on quality of life. Ann Nutr Metab. 2015;66(suppl 1):34-40. doi:10.1159/000370226

6. Blome C, Radtke MA, Eissing L, Augustin M. Quality of life in patients with atopic dermatitis: disease burden, measurement, and treatment benefit. Am J Clin Dermatol. 2016;17(2):163-169. doi:10.1007/s40257-015-0171-3

7. Chiesa Fuxench ZC. Atopic dermatitis: disease background and risk factors. Adv Exp Med Biol. 2017;1027:11-19. doi:10.1007/9783-319-64804-0_2

8. Barbarot S, Auziere S, Gadkari A, et al. Epidemiology of atopic dermatitis in adults: results from an international survey. Allergy Eur J Allergy Clin Immunol. 2018;73(6):1284-1293. doi:10.1111/ all.13401

9. Hay RJ, Johns NE, Williams HC, et al. The global burden of skin disease in 2010: an analysis of the prevalence and impact of skin conditions. J Invest Dermatol. 2014;134(6):1527-1534. doi:10.1038/ jid.2013.446

10. Laughter MR, Maymone MBC, Mashayekhi S, et al. The global burden of atopic dermatitis: lessons from the Global Burden of Disease Study 1990-2017*. Br J Dermatol. 2021;184(2):304-309. doi:10.1111/bjd.19580

11. Odhiambo JA, Williams HC, Clayton TO, Robertson CF, Asher MI; ISAAC Phase Three Study Group. Global variations in prevalence of eczema symptoms in children from ISAAC Phase Three. $J$ Allergy Clin Immunol. 2009;124(6):1251-1258.e23. doi:10.1016/j.jaci.200 9.10.009

12. Kumar MK, Singh PK, Tahir MMA. The clinico-epidemiological profile and the risk factors associated with the severity of atopic dermatitis (AD) in eastern Indian children. J Clin Diagnostic Res. 2012;6(7 SUPPL):1162-1166.

13. Sehgal V, Srivastava G, Aggarwal A, Saxena D, Chatterjee K, Khurana A. Atopic dermatitis: a cross-sectional (descriptive) study of 100 cases. Indian J Dermatol. 2015;60(5):519. doi:10.4103/00195154.164412

14. Jawade SA, Chugh VS, Gohil SK, Mistry AS, Umrigar DD. A clinico-etiological study of dermatoses in pediatric age group in tertiary health care center in South Gujarat region. Indian J Dermatol. 2015;60(6):635. doi:10.4103/0019-5154.169147

15. Upendra Y, Keswani N, Sendur S, Pallava A. The clinico-epidemiological profile of atopic dermatitis in residential school children: a study from South Chhattisgarh, India. Indian J Paediatr Dermatol. 2017;18(4):281. doi:10.4103/ijpd.ijpd_52_17

16. Tsai TF, Rajagopalan M, Chu CY, et al. Burden of atopic dermatitis in Asia. J Dermatol. 2019;46(10):825-834. doi:10.1111/1346-8138.1 5048

17. Kanwar A, De D. Epidemiology and clinical features of atopic dermatitis in India. Indian J Dermatol. 2011;56(5):471. doi:10.4 103/0019-5154.87112

18. Senra MS, Wollenberg A. Psychodermatological aspects of atopic dermatitis. Br J Dermatol. 2014;170(SUPPL. 1):38-43. doi:10.1111/ bjd. 13084

19. Handa S, Jain N, Narang T. Cost of care of atopic dermatitis in India. Indian J Dermatol. 2015;60(2):213. doi:10.4103/0019-5154.152573

20. Rajagopalan M, De A, Godse K, et al. Guidelines on management of atopic dermatitis in India: an evidence-based review and an expert consensus. Indian J Dermatol. 2019;64(3):166. doi:10.4103/ijd. IJD_683_18

21. Sathishkumar D, Gupta A, Saini K. Atopic dermatitis in children: an update for pediatricians. Curr Med Issues. 2020;18(4):317. doi:10.4103/cmi.cmi_81_20 
22. Eichenfield LF, Tom WL, Chamlin SL, et al. Guidelines of care for the management of atopic dermatitis: section 1. Diagnosis and assessment of atopic dermatitis Work Group. J Am Acad Dermatol. 2014;70 (2):338-351. doi:10.1016/j.jaad.2013.10.010

23. Vakharia PP, Chopra R, Silverberg JI. Systematic review of diagnostic criteria used in atopic dermatitis randomized controlled trials. $\mathrm{Am}$ J Clin Dermatol. 2018;19(1):15-22. doi:10.1007/s40257-017-0299-4

24. Silvestre Salvador J, Romero-Pérez D, Encabo-Durán B. Atopic dermatitis in adults: a diagnostic challenge. J Investig Allergol Clin Immunol. 2017;27(2):78-88. doi:10.18176/jiaci.0138

25. Sinclair W, Aboobaker J, Green RJ, Levin ME. Diagnosis of atopic dermatitis: from bedside to laboratory. South African Med J. 2014;104(10):711. doi:10.7196/SAMJ.8850

26. Kim JP, Chao LX, Simpson EL, Silverberg JI. Persistence of atopic dermatitis (AD): a systematic review and meta-analysis. J Am Acad Dermatol. 2016;75(4):681-687.e11. doi:10.1016/j.jaad.2016.05.028

27. Dhar S, Bisweswar Mandal AG. Epidemiology and clinical pattern of atopic dermatitis in 100 children seen in a city hospital. Indian J Dermatol. 2002;47(4):202-204.

28. Yang G, Seok JK, Kang HC, Cho YY, Lee HS, Lee JY. Skin barrier abnormalities and immune dysfunction in atopic dermatitis. Int J Mol Sci. 2020;21(8):1-14. doi:10.3390/ijms21082867

29. Magnifico I, Petronio GP, Venditti N, et al. Atopic dermatitis as a multifactorial skin disorder. Can the analysis of pathophysiological targets represent the winning therapeutic strategy? Pharmaceuticals. 2020;13(11):1-18. doi:10.3390/ph13110411

30. Totte JEE, van der Feltz WT, Hennekam M, van Belkum A, van Zuuren EJ, Pasmans SGMA. Prevalence and odds of S taphylococcus aureus carriage in atopic dermatitis: a systematic review and meta-analysis. Br J Dermatol. 2016;175(4):687-695. doi:10.1111/ bjd. 14566

31. Kurien G, Divakaran MV, Sadanandan SM, Sobhanakumari K, Sarin A, Jagadeesan S. Methicillin-resistant Staphylococcus aureus colonization and disease severity in atopic dermatitis: a cross-sectional study from South India. Indian J Dermatol, Venereol Leprol. 2014;80(3):229-234. doi:10.4103/0378-6323.132250

32. Langan SM, Irvine AD, Weidinger S. Atopic dermatitis. Lancet. 2020;396(10247):345-360. doi:10.1016/S0140-6736(20)31286-1

33. LeBovidge JS, Elverson W, Timmons KG, et al. Multidisciplinary interventions in the management of atopic dermatitis. J Allergy Clin Immunol. 2016;138(2):325-334. doi:10.1016/j.jaci.2016.04.003

34. Frazier W, Bhardwaj N. Atopic dermatitis: diagnosis and treatment. Am Fam Physician. 2020;101(10):590-598.

35. Nankervis H, Thomas KS, Delamere FM, Barbarot S, Rogers NK, Williams HC. Scoping systematic review of treatments for eczema. Program Grants Appl Res. 2016;4(7):1-480. doi:10.3310/pgfar04070
36. Green C, Colquitt JL, Kirby J, Davidson P. Topical corticosteroids for atopic eczema: clinical and cost effectiveness of once-daily vs. more frequent use. $\mathrm{Br} J$ Dermatol. 2005;152(1):130-141. doi:10.1111/ j.1365-2133.2005.06410.x

37. Berke R, Singh A, Guralnick M. Atopic dermatitis: an overview. Am Fam Physician. 2012;86(1):35-42.

38. Drucker AM, Eyerich K, de Bruin-Weller MS, et al. Use of systemic corticosteroids for atopic dermatitis: international Eczema Council consensus statement. $\mathrm{Br} \quad J$ Dermatol. 2018;178(3):768-775. doi:10.1111/bjd.15928

39. Yu SH, Drucker AM, Lebwohl M, Silverberg JI. A systematic review of the safety and efficacy of systemic corticosteroids in atopic dermatitis. $J$ Am Acad Dermatol. 2018;78(4):733-740.e11. doi:10.1016/j.jaad.2017.09.074

40. Sidbury R, Davis DM, Cohen DE, et al. Guidelines of care for the management of atopic dermatitis: section 3. Management and treatment with phototherapy and systemic agents. J Am Acad Dermatol. 2014;71(2):327-349. doi:10.1016/j.jaad.2014.03.030

41. Garritsen FM, Brouwer MWD, Limpens J, Spuls PI. Photo(chemo) therapy in the management of atopic dermatitis: an updated systematic review with implications for practice and research. Br J Dermatol. 2014;170(3):501-513. doi:10.1111/bjd.12645

42. Rashmi Sarkar AJK. Clinico-epidemiological profile and factors affecting severity of atopic dermatitis in north Indian children. Indian J Dermatol. 2004;49(3):117-122.

43. Karthikeyan K, Thappa DM, Jeevankumar B. Pattern of pediatric dermatoses in a referral center in South India. Indian Pediatr. 2004;41(4):373-377.

44. Handa S, Khullar G, Pal A, Kamboj P, De D. Filaggrin gene mutations in hand eczema patients in the Indian subcontinent: a prospective case-control study. Contact Dermatitis. 2019;80 (6):359-364. doi:10.1111/cod.13233

45. Jain C, Das S, Ramachandran VG, Saha R, Bhattacharya SN, Dar S. Malassezia yeast and cytokine gene polymorphism in atopic dermatitis. J Clin Diagnostic Res. 2017;11(3):DC01-DC05. doi:10.7860/JCDR/2017/23948.9474

46. Dhar S, Kanwar AJ. Epidemiology and clinical pattern of atopic dermatitis in a north Indian pediatric population. Pediatr Dermatol. 1998;15(5):347-351. doi:10.1046/j.1525-1470.1998.1998015347.x

47. Kim JE, Kim HJ, Lew BL, et al. Consensus guidelines for the treatment of atopic dermatitis in Korea (part II): systemic treatment. Ann Dermatol. 2015;27(5):578-592. doi:10.5021/ad.2015.27.5.578

48. Fujii M. Current understanding of pathophysiological mechanisms of atopic dermatitis: interactions among skin barrier dysfunction, immune abnormalities and pruritus. Biol Pharm Bull. 2020;43 (1):12-19. doi:10.1248/bpb.b19-00088
Clinical, Cosmetic and Investigational Dermatology

\section{Publish your work in this journal}

Clinical, Cosmetic and Investigational Dermatology is an international, peer-reviewed, open access, online journal that focuses on the latest clinical and experimental research in all aspects of skin disease and cosmetic interventions. This journal is indexed on CAS.
The manuscript management system is completely online and includes a very quick and fair peer-review system, which is all easy to use. Visit http://www.dovepress.com/testimonials.php to read real quotes from published authors. 